\title{
O ACADÊMICO INGRESSANTE NA EDUCAÇÃO SUPERIOR: PERFIL, ESCOLHAS E EXPECTATIVAS
}

\author{
UNIVERSITY ENTRANT IN HIGHER EDUCATION: \\ PROFILE, CHOICES AND EXPECTATIONSIi

\section{EL ESTUDIANTE QUE INGRESA EN LA EDUCACIÓN SUPERIOR: PERFIL, ELECCIONES Y EXPECTATIVAS}

\begin{abstract}
Cassia Ferri ${ }^{1}$, Blaise Keniel da Cruz Duarte ${ }^{2}$, Adair Aguiar Neitzel ${ }^{3}$
RESUMO

Esta pesquisa, cujo tema é a Educação Superior, tem como objetivo discutir, por meio do perfil do acadêmico ingressante, as pluralidades que compõem o mosaico juvenil e envolvem a transição do Ensino Médio para o Ensino Superior. Busca, ainda, pontuar ações que interferem na permanência do estudante na universidade. A metodologia utilizada é quali-quantitativa. $O$ instrumento de coleta de dados foi um questionário on-line com 19 questões objetivas aplicado a ingressantes da graduação de uma universidade do sul do Brasil em 2016, 1․ . semestre. A análise dos dados pautou-se na estratégia da triangulação metodológica, que permite a combinação e o cruzamento de métodos e técnicas de pesquisa. Como resultados, sinalizamos: a) o perfil dos ingressantes revela, entre outros dados, que a maioria é do sexo feminino, economicamente dependente da família e oriunda das escolas públicas; b) a participação em atividades culturais, como teatro, cinema, shows e em atividades de lazer, como a prática de esportes, dança e academia, é moderada; c) ações de acolhimento e atendimento ao discente no curso e ações institucionais são fundamentais para que a transição de uma etapa escolar a outra dê-se de forma mais tranquila, assim como para a permanência do acadêmico na universidade; d) a maioria dos ingressantes deseja desenvolver habilidades para diferentes possibilidades profissionais e adquirir conhecimentos da área de cultura geral. Observamos que o processo de transição do Ensino Médio para o Ensino Superior é dependente não apenas da formação dos ingressantes, mas também da estrutura que os acolhe. A universidade necessita atuar como um campo de formação específica, mas também oferecer oportunidades de ampliar o capital cultural dos alunos.
\end{abstract}

PALAVRAS-CHAVE: Educação Superior. Perfil dos ingressantes. Cultura juvenil.

\section{ABSTRACT}

This research, whose theme is Higher Education, aims to discuss, through the profile of the university entrant, the pluralities that make up the juvenile mosaic, and involve the transition from High School to Higher Education. It also seeks to point out some actions that interfere in the student's permanence in the university. The methodology used is qualitative and quantitative. The data collection instrument was an on-line questionnaire with nineteen objective questions applied to entrants of undergraduation courses at a University located in the South of Brazil, in 2016, $1^{\text {st }}$ semester. The analysis of the data was based on the strategy of methodological triangulation, which allows the combination and crossing of research methods and techniques.

\footnotetext{
${ }^{1}$ Doutora em Educação - Pontifícia Universidade Católica de São Paulo (PUC-SP), São Paulo, SP - Brasil. Professora do Mestrado e Doutorado - Universidade do Vale do Itajaí (UNIVALI) - Itajaí, SC - Brasil. E-mail: cassia@univali.br

${ }^{2}$ Doutora em Educação - Universidade do Vale do Itajaí (UNIVALI) - Itajaí, SC. Brasil. Professora da graduação da UNIVALI - Itajají, SC - Brasil. E-mail: blaise@univali.br

${ }^{3}$ Doutora em Literatura - Universidade Federal de Santa Catarina (UFSC), Florianópolis, SC - Brasil. Professora do mestrado e doutorado - Universidade do Vale do Itajaí (UNIVALI) - Itajaí, SC - Brasil. E-mail:
} neitzel@univali.br

Submetido em: 09/05/2017 - Aceito em: 08/05/23018

(C) ETD-Educação Temática Digital Campinas, SP $\quad$ v.20 $\quad$ n.3 $\quad$ p. 781--804 jul./set. 2018


The results show that: a) the profile of the university entrants reveals, among other data, that the majority are female; they are economically dependent on their families and come from public schools; b) the participation in cultural activities such as theater, cinema, shows and in leisure activities such as sports, dance and keep fit is moderate; c) the actions of welcoming and attending to students in the course and institutional actions are essential so that the transition from one school stage to another occurs in a calm way, and for ensuring the permanence of the student in the university; d) the majority of university entrants want to develop skills for different professional opportunities, and to acquire specific knowledge in the area of general culture. We observed that the process of transition from High School to Higher Education is dependent not only on the education they receive, but also on the structure that receives them. The university must act as a field of specific education, but it must also offer opportunities to increase the cultural capital of the students.

KEYWORDS: Higher Education. Profile of the university entrants. Youth culture.

\section{RESUMEN}

Esta investigación tiene como tema la Educación Superior y su objetivo es discutir las pluralidades que componen el mosaico juvenil e involucran la transición de la Enseñanza Secundaria hacia la Superior por medio del perfil del alumno ingresante. Buscamos, además, destacar las acciones que interfieren en la permanencia del estudiante en la universidad. La metodología utilizada es cuali-cuantitativa. El instrumento para recoger los datos fue un cuestionario on line con 19 preguntas objetivas aplicado a los ingresantes en las carreras de grado en el primer semestre de 2016 en la Universidade del sur de Brasil. El análisis del instrumento se pautó en la estrategia de la triangulación metodológica, que permite la combinación y el cruce de métodos y técnicas de investigación. Como resultados señalamos: a) el perfil de los ingresantes revela, entre otros datos, que la mayoría es del sexo femenino, son económicamente dependientes de la familia y oriundos de escuelas públicas; b) la participación en actividades culturales como teatro, cine, shows y en actividades de ocio tales como la práctica de deportes, baile y gimnasia es moderada; c) que las acciones de recepción y atención al discente, acciones a lo largo del curso e institucionales son fundamentales para que la transición del estudiante ocurra de forma más tranquila, así como para su permanencia en la universidad; d) la mayoría desea desarrollar habilidades para diferentes posibilidades profesionales y adquirir conocimiento específico del área y cultura general. Observamos que la transición del alumno no depende solamente de la formación de los ingresantes, sino también de la estructura que los acoge. La universidad necesita actuar como un campo de formación específica, pero también ofrecer oportunidades de ampliar su capital cultural.

PALABRAS CLAVE: Educación Superior. Perfil de los ingresantes. Cultura juvenil.

\section{INTRODUÇÃO}

Para discutirmos a Educação Superior no século XXI, podemos partir de vários dados e pressupostos, como as estatísticas do Instituto Nacional de Estudos e Pesquisas Educacionais Anísio Teixeira (INEP) sobre o número de vagas disponíveis aos graduandos, a missão e o perfil das universidades, a função dos docentes, o compromisso social da universidade a partir de suas reais finalidades, o perfil discente, entre outros. Este estudo aborda a temática a partir da caracterização do perfil dos estudantes ingressantes, em 2016, em uma universidade situada no litoral centro-norte do estado de Santa Catarina, Região Sul do Brasil. Discutimos as pluralidades que compõem o mosaico juvenil e envolvem a transição do Ensino Médio para o Ensino Superior por meio do perfil do acadêmico ingressante. Buscamos, ainda, pontuar ações de integração que interferem na permanência do estudante na universidade.

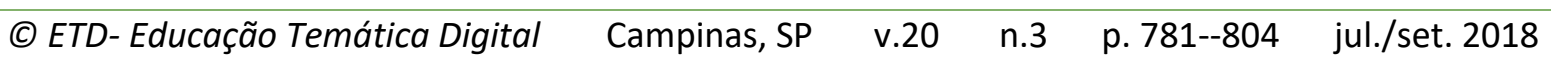


Raitz e Figuera-Gazo (2015, p. 5), ao pesquisarem sobre essa temática no entorno ibero-americano, pontuam que a "[...] dimensão social é uma das apostas chave da universidade atual [...]" e que a compreensão dessa dimensão implica garantir não só o acesso dos estudantes à Educação Superior, mas também a qualidade da educação para a promoção desse público. Segundo as pesquisadoras, pensar na dimensão social da universidade é minimizar o fracasso e o abandono universitário, e prover a gestão da diversidade de recursos para a implementação de mecanismos que diminuam os obstáculos enfrentados pelos estudantes para se manterem na universidade. As pesquisas que as autoras trazem à baila atestam que "[...] os sistemas educativos de todo o mundo apresentam em comum a problemática das transições educativas e o abandono educativo precoce, fenômeno que tem se tornado difícil de gestionar" (RAITZ; FIGUERA-GAZO, 2015, p. $6)$.

No cenário brasileiro, a meta 12 do Plano Nacional de Educação 2014-2024 (Lei № 13.005, de 25 de junho de 2014) prevê a ampliação do acesso à Educação Superior, cuja porcentagem de matrículas entre a população brasileira de 18 a 24 anos, em 2015, era de 18,1\% (BRASIL, 2014). Estima-se alcançar 33\% até 2024. Os dados divulgados pelo INEP sobre o censo do Ensino Superior de 2015 revelam que 90,68\% das vagas novas nesse nível de ensino são de responsabilidade do setor privado, informação que nos convida a refletir sobre a necessidade de a universidade se mobilizar para ampliar sua percepção sobre os estudantes ingressantes.

Os aspectos relacionados à entrada na Educação Superior fazem parte de indicadores de avaliação que nos auxiliam a discutir a qualidade da educação. Quando geram estímulos, os processos de avaliação servem de alavanca, de mudança e transformação (GATTI, 2000). "Os processos avaliativos são, assim, parte integrante de nosso dia a dia, ajudam-nos a processar mudanças ou a reforçar caminhos e rotinas, a cessar ações [...]" (GATTI, 2000, p. 93).

Para Gatti (2000), a definição do contexto de referência e dos objetivos da avaliação é fundamental para que esta tenha cunho científico e sentido social. Além disso, a reflexão sobre os fundamentos da avaliação é que vai dar legitimidade ao processo avaliativo, o que sinalizará a relevância do contributo representado por esse processo.

Considerando-se que, na Educação Superior, lidamos com fenômenos humanos e educacionais e, portanto, com processos que implicam diretamente a vida de pessoas, a análise dos dados da avaliação institucional sobre o perfil dos ingressantes em uma instituição de Ensino Superior permite-nos problematizar sobre as possibilidades de adaptação dos acadêmicos. Essa análise pode contribuir para gerar políticas institucionais que busquem não apenas melhor qualificação profissional - ou melhor, desempenho do acadêmico -, mas também o reconhecimento de questões sobre o desenvolvimento do

(C) ETD-Educação Temática Digital $\quad$ Campinas, SP $\quad$ v.20 $\quad$ n.3 $\quad$ p. 781--804 jul./set. 2018


estudante e sobre as oportunidades que este encontra de escolher o projeto que deseja para si.

\section{METODOLOGIA}

A metodologia utilizada é quali-quantitativa e o instrumento de coleta de dados consta de um questionário on-line com 19 perguntas objetivas respondido por 2.264 ingressantes no primeiro semestre de 2016 , o que correspondeu a $62,18 \%$ do número total de ingressantes na instituição que era, então, de 3.641. Esse questionário apresenta duas dimensões: Perfil acadêmico e familiar e Escolhas e expectativas do acadêmico. $\mathrm{Na}$ primeira dimensão, apuramos características pessoais do respondente, condições socioeconômicas da família, onde cursou o Ensino Médio, ocupação profissional, atividades culturais e de lazer, recursos que mais utiliza para estudar, horas que dedica à leitura fora da universidade, conhecimento de língua estrangeira e acesso à internet. Na segunda dimensão, visamos a perceber como foi informado sobre a universidade e o curso, a motivação para a escolha da instituição e do curso, as expectativas em relação ao curso e o município de origem.

Assegura-se a confiabilidade dos dados assim como os cuidados éticos necessários a toda pesquisa pelo fato de o Programa de Avaliação Institucional da Universidade, implantado desde a década de 1990, realizar anualmente campanha na instituição, mobilizando todos os estudantes matriculados a participarem da pesquisa de avaliação. Assim, a adesão não é obrigatória, mas faz parte da rotina dessa instituição. Os estudantes acessam a intranet com o código de aluno, no link Pesquisa Online, manifestando o aceite ou não para responderem ao instrumento. Desse modo, todas as informações ficam registradas em um sistema do qual parte do banco de dados foi disponibilizado aos pesquisadores.

A análise dos dados pautou-se na estratégia da triangulação metodológica, que permite combinação e cruzamento de métodos e técnicas de pesquisa. Essa análise permitiu-nos discutir as pluralidades que compõem o mosaico juvenil e envolvem a transição do Ensino Médio para o Ensino Superior por meio do perfil do acadêmico ingressante, assim como trazer à baila políticas públicas ou institucionais que margeiam o processo de ingresso dos estudantes na Educação Superior.

\section{CARACTERÍSTICAS APURADAS: CONHECENDO MAIS O ESTUDANTE INGRESSANTE}

A aplicação de um questionário a acadêmicos ingressantes acerca do perfil pessoal desse segmento permite-nos compreender a realidade que cerca esses estudantes e identificar os fatores que dificultam ou favorecem a inserção deles na universidade. Em
(C) ETD-Educação Temática Digital
Campinas, SP
v. 20
n. 3
p. $781--804$
jul./set. 2018 
2016, identificamos que $56,54 \%$ dos discentes que responderam ao questionário da avaliação institucional eram do sexo feminino. De acordo com dados da Pesquisa Nacional por Amostra de Domicílio/PNAD 2014 relacionados à escolarização, a população feminina a partir de 10 anos de idade apresenta médias maiores de anos de estudo em todas as regiões do país. A mesma pesquisa aponta que, no Brasil, estudantes do sexo feminino são maioria no Ensino Superior, situação que se confirma também pela análise dos dados coletados na avaliação institucional junto aos acadêmicos ingressantes na universidade pesquisada, conforme se pode verificar no Gráfico 1. A participação da mulher na universidade, que sinaliza a "[...] busca por direito de igualdade, orientada pela elevação da participação da mulher nas decisões sociais e na conquista do movimento feminista, tem configurado novo cenário para as mulheres do século XXI" (SILVA FILHO; QUEIROZ; CLEMENTINO, 2016, p. 37). O curso superior é percebido como uma oportunidade de sucesso no mercado de trabalho, ampliando o crescimento da atividade feminina, como afirma Bruschini (2007), pois a escolaridade elevada impacta o tipo de trabalho a ser desenvolvido.

Gráfico 1: Ingressantes nos cursos de graduação da universidade por sexo

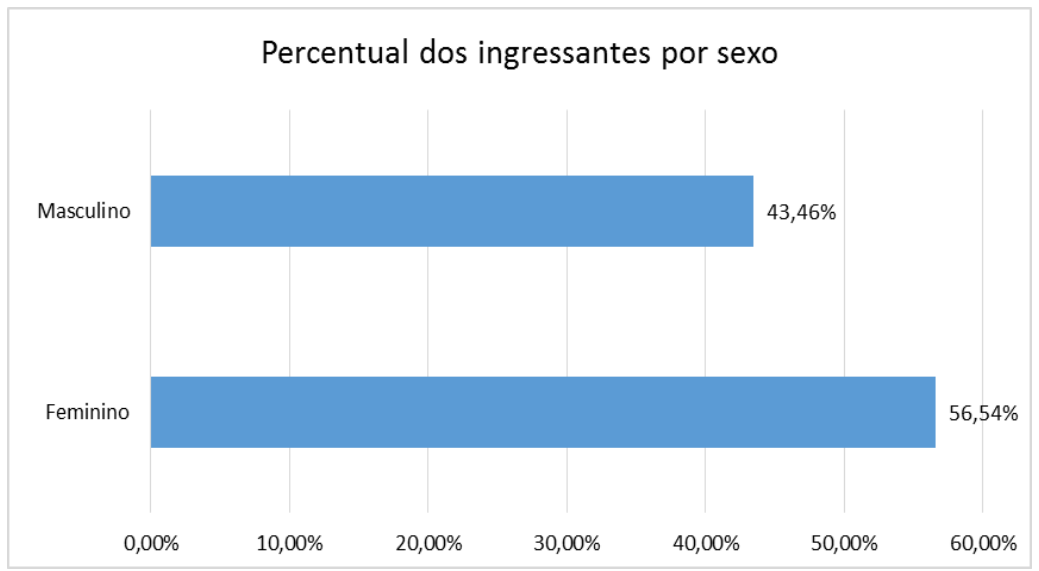

Fonte: Vice-Reitoria de Graduação e Gerência de Ensino e Avaliação da universidade investigada/2016.

Identificamos, ainda, que esse grupo de universitários é bastante jovem, cerca de $88 \%$ têm até 25 anos. A população jovem abrange a faixa etária de 15 a 29 anos, conforme a Constituição Brasileira (BRASIL, 1988) e o Estatuto da Juventude (BRASIL, 2013), sancionado em 5 de agosto de 2013. Segundo Zluhan e Raitz (2014, p. 2), “[...] essa faixa etária é caracterizada como um período de conflitos, divergências e desordens, por meio de vários estereótipos e pela homogeneização da cultura juvenil", que são agravados pela condição de ansiedade diante da provisoriedade e das incertezas da sociedade moderna.

Além de terem um perfil jovem, 71\% são economicamente dependentes da família, apesar de 46,55\% desempenharem alguma atividade profissional concomitante aos estudos. Esse dado permite-nos inferir que, apesar de um percentual alto já ter ingressado no mundo
(C) ETD-Educação Temática Digital
Campinas, SP
v. 20
n.3
p. $781--804$
jul./set. 2018 
do trabalho, desempenhando uma atividade produtiva financeiramente, a renda não é suficiente para que se mantenham independentes economicamente da família. $\mathrm{O}$ salário recebido por estágio não obrigatório ou trabalho vem complementar a renda familiar.

Cursar uma universidade privada ou comunitária nem sempre é compatível com a situação financeira do estudante da escola pública, mas é da rede pública de ensino que provêm 59,54\% dos acadêmicos ingressantes que participaram desta pesquisa. 0 índice pode ser justificado pelas políticas públicas implementadas no país (incremento no Fundo de Financiamento Estudantil - FIES e Programa Universidade para Todos - PROUNI), que contribuíram para ampliar o acesso ao ensino universitário entre esse segmento. Ao longo de seis anos, houve um aumento substancioso no número de bolsas do PROUNI, como podemos observar a seguir.

Gráfico 2: Número de bolsas PROUNI concedidas a acadêmicos matriculados entre o primeiro semestre de 2010 e o segundo semestre de 2016

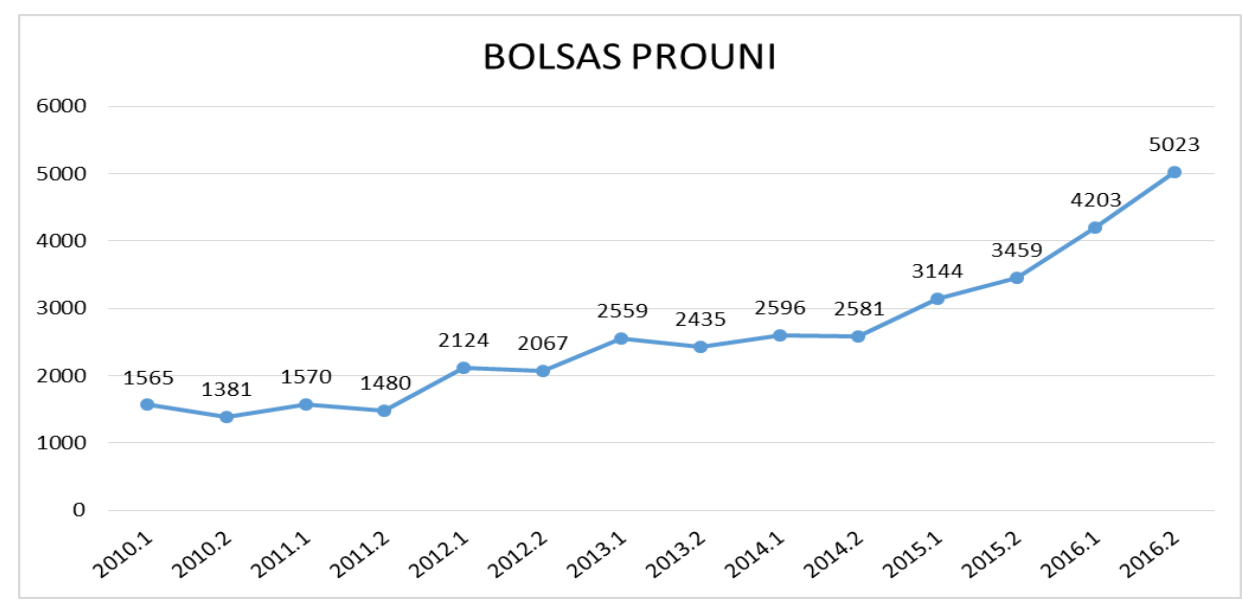

Fonte: Vice-Reitoria de Graduação e Gerência de Ensino e Avaliação da universidade investigada/2016.

Vanzuita et al. (2016, p. 1) observam que: "O ingresso dos alunos provenientes da rede pública ao Ensino Superior é crescente, exigindo que os órgãos gestores dessas instituições tenham um olhar atento acerca do atendimento". Além do PROUNI, outras políticas públicas, como o Programa Institucional de Bolsas de Iniciação à Docência (PIBID), Programa de Educação Superior para o Desenvolvimento Regional (Proesde Licenciatura), Fundo de Apoio à Manutenção e ao Desenvolvimento da Educação Superior (Fumdes), Fumdes Licenciatura, Programa dos artigos 170 e 171 da Constituição do Estado de Santa Catarina, Fundo Social e PROUNI Filantropia, assim como bolsas de pesquisa e extensão, também incentivaram o acesso e a permanência na universidade. 
Essas políticas públicas permitem um ingresso maior de estudantes na universidade privada; no entanto, a permanência deles depende não apenas da viabilidade econômica. Para que o ingressante estabeleça vínculos com a instituição, ele precisa não somente apropriar-se da rotina institucional, o que envolve ações no curso acerca do seu funcionamento, mas também de acolhimento. Para Vanzuita et al. (2016, p. 1), caberá à instituição prover meios para auxiliar os acadêmicos a "[...] superar seus obstáculos iniciais, habilitando-os para que tenham oportunidade de buscar sua formação universitária".

A universidade pesquisada propõe várias ações por meio de projetos que, a partir dos dados coletados no Programa de Avaliação Institucional, foram implantados, como o Programa de Atenção a Discentes, Egressos e Funcionários (PADEF), o qual impactou diretamente as ações psicoeducacionais de atendimento ao discente. Após dez anos de implantação, o programa foi redimensionado para dar lugar ao Núcleo de Acessibilidade da Universidade (NAU). Este tem como objetivo acolher o estudante diagnosticado com necessidades especiais e acompanhar sua trajetória de aprendizagem no ambiente acadêmico. Além do NAU, como parte da política institucional de acolhimento, citamos a Gerência de Atenção ao Estudante (GAE), que planeja, supervisiona e executa os procedimentos referentes à administração da vida do acadêmico, entre eles, o gerenciamento de processos de bolsas de estudo e financiamentos estudantis. Outra Gerência - a de Ensino e Avaliação (GEA) - planeja e implementa ações de formação continuada para os docentes, duas vezes ao ano, com o propósito de refletir sobre os processos pedagógicos, melhorar a aprendizagem e a acolhida do acadêmico na universidade. Faz parte da formação continuada docente o estudo do perfil dos universitários ingressantes e egressos, tarefa para a qual contribuem os dados do questionário sobre o perfil dos ingressantes, ora em análise. Entendemos, portanto, que um instrumento dessa natureza, quando analisado em uma perspectiva formativa, traz implicações psicoeducacionais, pois, por meio dele, ações voltadas à formação continuada dos professores são acionadas. Essas ações podem possibilitar melhorias institucionais, as quais impactam diretamente na relação professor e aluno, por meio da realização de estudos e de discussões nos cursos; aprimoramento do atendimento ao ingressante, bem como busca por oportunidades de bolsas e ampliação de espaços para realização de pesquisa e extensão.

Entre os dados coletados, um é o que se refere à participação dos ingressantes em atividades socioculturais. Observamos que $25,5 \%$ não participam de nenhuma atividade sociocultural, como ir ao cinema, ao teatro ou a shows. Nesse grupo de estudantes, podem estar parte dos que desempenham alguma atividade profissional concomitante aos estudos (46,55\% dos participantes da pesquisa afirmam estar nessa situação). Chama atenção que $77,4 \%$ dos estudantes afirmam participar de atividades socioculturais, e 50,61\% deles vão a
(C) ETD-Educação Temática Digital
Campinas, SP
v. 20
n. 3
p. $781--804$
jul./set. 2018 
shows, teatro e cinema de 2 a 5 vezes por semana. Esses números sugerem uma prontidão dos alunos ingressantes para participar de atividades dessa natureza caso sejam oferecidas pela universidade. Evidenciam, ainda, a importância de a universidade ser percebida também como espaço de experiências culturais, de trocas, de encontros que proporcionem oportunidades de o aluno ampliar seu capital cultural.

Gráfico 3: Frequência em atividades socioculturais

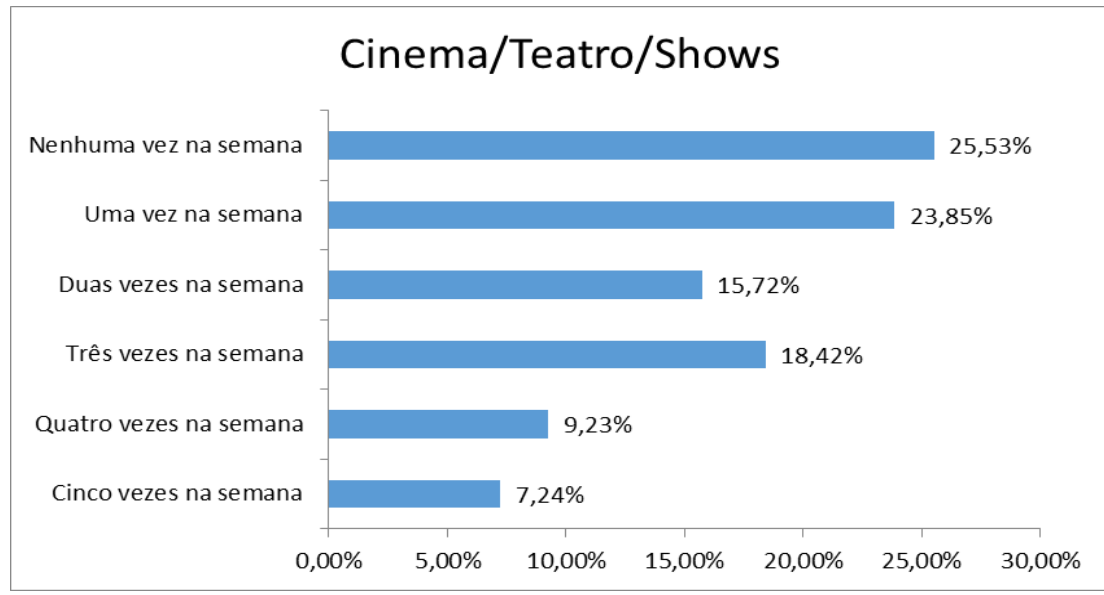

Fonte: Vice-Reitoria de Graduação e Gerência de Ensino e Avaliação da universidade investigada/2016.

Neitzel, Carvalho e Bridon (2015) apresentam pesquisas que exemplificam como o processo de ensino - aprendizagem exige ações criadoras, de cognição e reflexão, seja dos alunos ou dos professores. Há evidências de como a experiência cultural amplia a educação estética, impacta a formação profissional e impulsiona as ações criadoras, ressaltando a experiência do mundo sensível como via de acesso ao conhecimento.

Os estudos de Mendes e Costa (2015) buscam verificar qual a influência das chamadas práticas culturais nas realizações e no alcance educacional, explorando a influência dos recursos familiares e dos hábitos culturais dos jovens no acesso à Educação Superior. Segundo os pesquisadores, o acesso dos estudantes a diferentes práticas é limitado por diversas razões: econômicas, sociais, políticas. Os autores sinalizam que "[...] o Capital Cultural cria nos indivíduos as predisposições necessárias para que se adequem ao sistema escolar através de um habitus de estudante ligado à cultura dominante" (MENDES; COSTA, 2015, p. 19). Os pesquisadores apontam para as influências desse capital cultural no desempenho escolar e a pertinência de a universidade não se isentar de seu papel diante dessa problemática, pois as aprendizagens "[...] acontecem não apenas por experiências cognitivas, mas também pelos sentidos e pelos afetos" (URIARTE; NEITZEL; CARVALHO, 2016, p. 187).

Se considerarmos a leitura como outra possibilidade de ampliar-se o capital cultural dos alunos, constataremos a necessidade de ações na universidade que instiguem esse ato
(C) ETD-Educação Temática Digital
Campinas, SP
v. 20
n. 3
p. $781--804$
jul./set. 2018 
em sala de aula e fora dela, porque, ao serem questionados acerca do número de horas que dedicam à leitura fora da universidade, apenas 23,94\% disseram ler três vezes por semana; e $21,33 \%$, cinco vezes por semana. Importante pontuar que o instrumento não qualifica o tipo de leitura, se funcional ou de fruição, se em meio digital ou impresso. Esse dado é relevante porque, ao mesmo tempo que se observa falta de vínculo com a leitura, estamos vivendo um momento de mutação com os novos suportes digitais. Como afirma Poulain (2012, p. 69): "Ce phénomène de désaffection apparente pour la lectures'est manifesté à un moment de grandes politiques de lecture innovantes".

Gráfico 4: Frequência de leitura

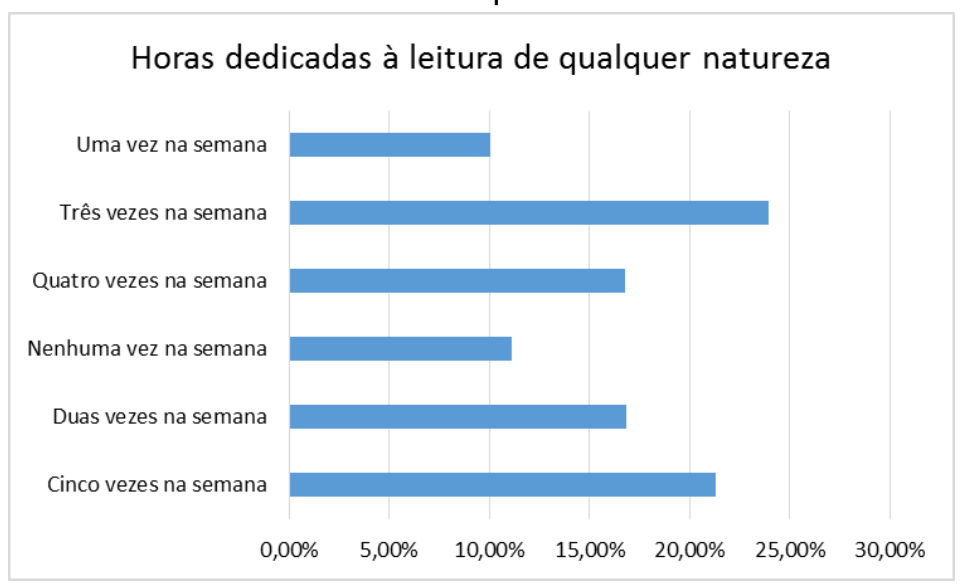

Fonte: Vice-Reitoria de Graduação e Gerência de Ensino e Avaliação da universidade investigada/2016.

Temos aqui uma evidência forte da necessidade de projetos ou ações que promovam a leitura, motor de autoformação e autorregulação da aprendizagem. Não dedicar um tempo mínimo para as exigências escolares que requerem leitura irá provocar impacto no desempenho acadêmico. Bridon e Neitzel (2014), ao observarem os níveis de compreensão leitora apontados por Gagné, Yekovich e Yekovich (1993), discutem sobre as competências de leitura adquiridas ao longo da escolarização do sujeito e de como elas acarretam dificuldades de aprendizagem, "[...] uma vez que o domínio de competências leitoras é fundamental para o acesso a várias áreas do conhecimento" (BRIDON; NEITZEL, 2014, p. 439).

Uma parcela dos respondentes declara não participar de esportes, dança e academia: $33,35 \%$ estão nesse grupo; $42,71 \%$ afirmam participar de uma a três vezes por semana; e $23,94 \%$ dos estudantes dizem praticar esporte, dança ou academia quatro a cinco vezes por semana. Percebemos, portanto, que a cultura do ler, do ir ao teatro, ao cinema, a shows, assim como a prática de dança e esportes, faz parte da vida de uma parcela significativa dos estudantes que entram na universidade, mas ainda temos um contingente de alunos que

(C) ETD-Educação Temática Digital $\quad$ Campinas, SP $\quad$ v.20 $\quad$ n.3 $\quad$ p. 781--804 jul./set. 2018


precisa criar hábitos culturais como a leitura diária e a participação em atividades culturais e esportivas.

Gráfico 5: Frequência com que praticam esportes, dança e academia

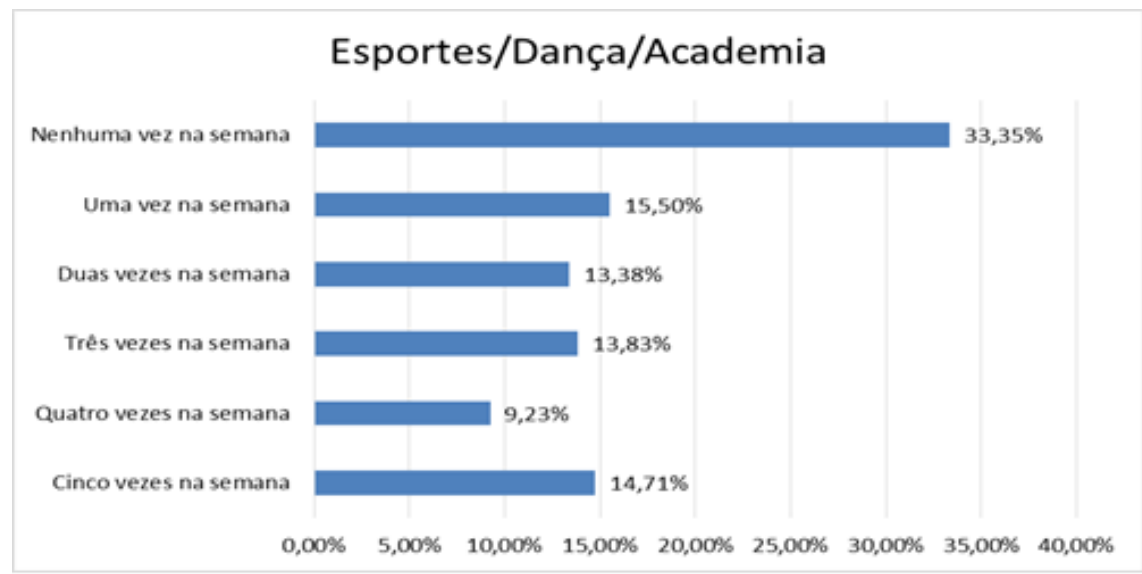

Fonte: Vice-Reitoria de Graduação e Gerência de Ensino e Avaliação da universidade investigada/2016.

Em parte, a cultura juvenil foi modificada pelo uso dos dispositivos tecnológicos móveis e das redes sociodigitais. A imersão nas culturas digitais provocou outros hábitos e mudanças na sociabilidade, na forma como as pessoas se relacionam. Para Lucena (2016, p. 288), faz-se necessário "[...] pensar nesse novo sujeito, praticante cultural que pensa, produz saberes e compartilha opiniões, conteúdos e informações nas redes". Contudo, o que faz esse jovem no seu tempo de ócio?

Gráfico 6: Atividades de lazer

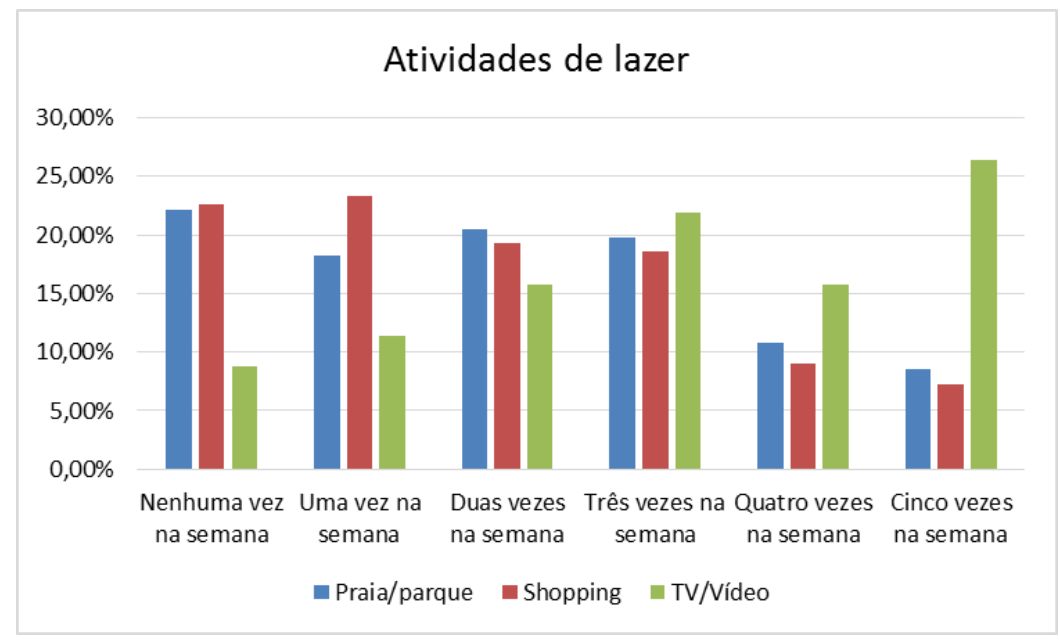

Fonte: Vice-Reitoria de Graduação e Gerência de Ensino e Avaliação da universidade investigada/2016.

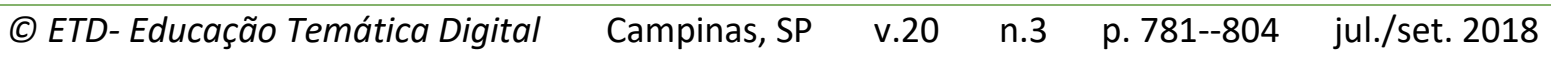


Segundo nossa pesquisa, a televisão, a praia, os parques e os shoppings são as alternativas de lazer que mais atraem os jovens ingressantes na universidade. É preciso considerar que o contexto geográfico em foco é litorâneo e urbano; desse modo, as atividades citadas não requerem muitos gastos. A TV e o vídeo destacam-se entre as opções mais apontadas: frequência de três, quatro e cinco vezes por semana. Zluhan, Vanzuita e Raitz (2017) observam que as formas de sociabilidade se modificaram, tendo em vista até o próprio desenvolvimento das cidades, e, hoje, as pessoas passaram a restringir o convívio social por questões de segurança.

Questionamos o jovem que acabou de ingressar na Educação Superior sobre que oportunidades ele tem de complementar sua formação por meio de outros cursos. Obtivemos o dado segundo o qual 59,98\% não fazem nenhum outro curso, 10,95\% afirmam fazer outro curso uma vez por semana e 19,13\%, de duas a três vezes por semana. Considerando que $71 \%$ são economicamente dependentes da família e que $46,55 \%$ desempenharam alguma atividade profissional concomitante aos estudos em 2016, entendemos que são poucas as oportunidades que esses jovens possuem de formação complementar. Esse resultado pode orientar um plano estratégico da gestão universitária para a oferta de atividades complementares no período das aulas, como eventos, seminários, bancas de Trabalho de Conclusão de Curso, um modelo que incorpore essa trajetória dos acadêmicos, ampliando as possibilidades humanas, como lembra Gatti (2000).

Gráfico 7: Frequência em outros cursos

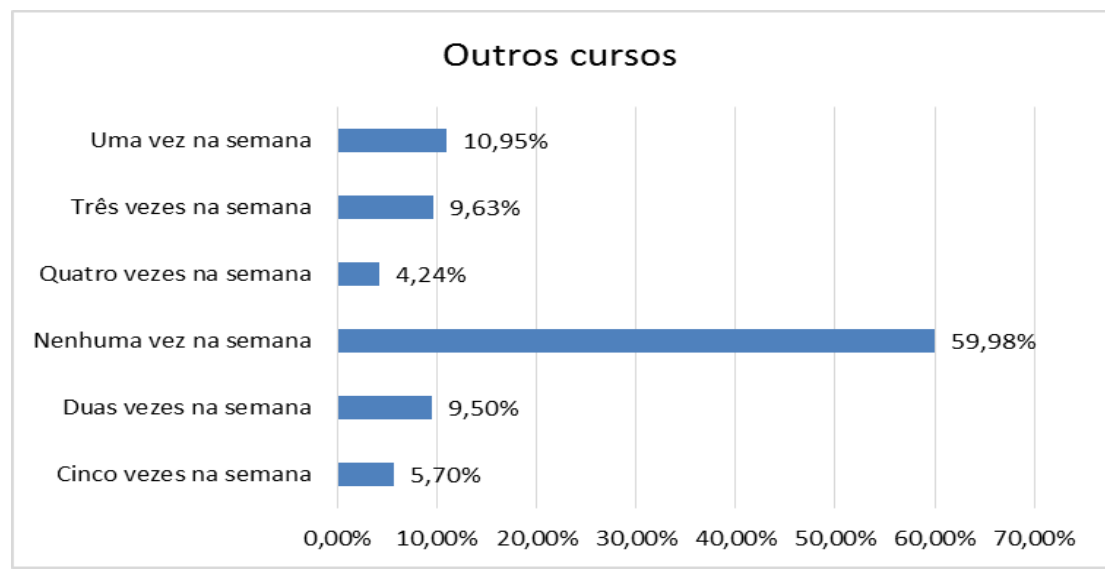

Fonte: Vice-Reitoria de Graduação e Gerência de Ensino e Avaliação da universidade investigada/2016.

Tendo em vista a dimensão social de uma instituição de Ensino Superior, podemos sinalizar a importância de uma universidade que se caracterize como campo de formação não apenas específica, mas generalista, isto é, uma formação que ofereça aos acadêmicos oportunidades de complementação profissional e ampliação desse campo, seja por meio de cursos ou de extensão e pesquisa. $\mathrm{Na}$ análise, deve-se considerar ainda o alto índice de ingressantes que não participam de atividades em organizações político-sociais: $56,67 \%$.

(C) ETD-Educação Temática Digital Campinas, SP $\quad$ v.20 $\quad$ n.3 $\quad$ p. $781--804 \quad$ jul./set. 2018


Gráfico 8: Participação em organizações político-sociais (frequência semanal)

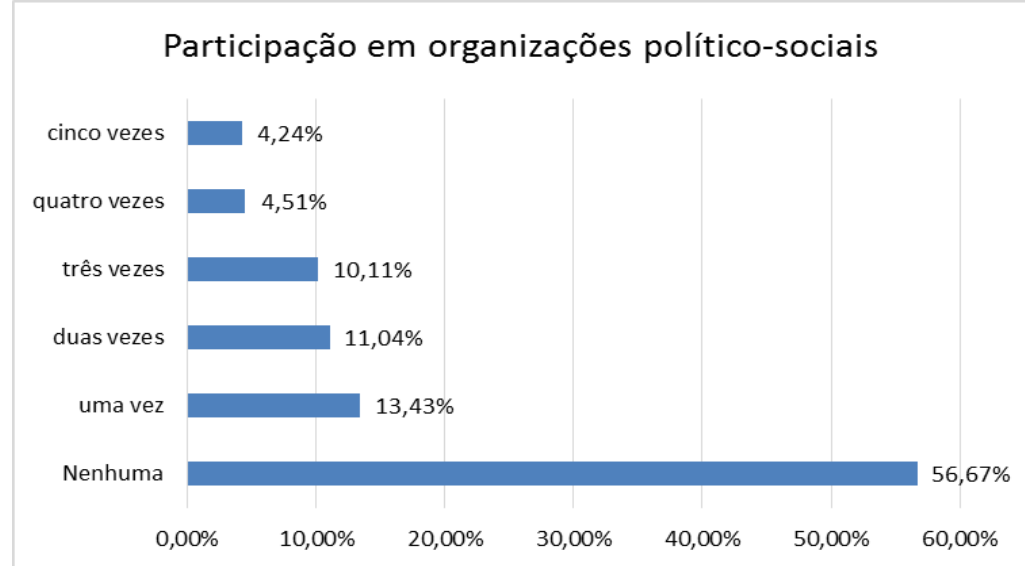

Fonte: Vice-Reitoria de Graduação e Gerência de Ensino e Avaliação da universidade investigada/2016.

Precisamos pontuar que, com o acesso e a participação dos jovens nas redes sociais, tornou-se mais comum essa faixa etária manifestar-se acerca dos acontecimentos sociais e políticos, mesmo que de forma rápida, instantânea e sem vínculo. No entanto, segundo Aderaldo e Raposo (2016, p. 300), ao analisarem movimentos audiovisuais e musicais juvenis organizados na metrópole paulistana e em Portugal, "[...] é no momento em que ocupam, por meio de suas práticas citadinas, os espaços urbanos, olhando-se nos olhos e reconhecendo-se como 'parceiros', que se constituem efetivamente como movimentos coletivos".

Percebemos, assim, que o pouco envolvimento dos ingressantes na universidade pesquisada com organizações como sindicatos, agremiações ou centros estudantis, sinaliza a necessidade de a universidade possibilitar atividades voltadas à coletividade, que permitam ao acadêmico exercitar o diálogo, o trabalho interdisciplinar, o convívio com os colegas. Essas oportunidades levam os acadêmicos à tomada de decisões regradas pelas condutas dos grupos, incorporando princípios de civilidade que ampliam e melhoram as relações interpessoais e o exercício de cidadania promotores de mudanças nos espaços onde atuam.

Importante notar que o ingresso na Educação Superior aponta, segundo os estudos do grupo de pesquisa Trals (2002, p. 5), da Universidade de Barcelona, para diferentes trajetórias de transição na universidade: "[...] de continuidade ou de abandono, de êxito na integração ou de fracasso na superação dos problemas gerados pela descontinuidade do ambiente educativo" ${ }^{4}$. O ingresso dos acadêmicos nesse novo ambiente exige deles um

\footnotetext{
4 “[...] de continuïtat o d'abandonament, d'èxit en la integració o de fracas em la superació dels problemes generats per la discontinuïtat d'ambients educatius" (TRALS, 2002, p. 5).
}
(C) ETD- Educação Temática Digital
Campinas, SP
v. 20
n. 3
p. 781--804
jul./set. 2018 
movimento de adaptação e, em muitos casos, de mudança de hábitos para que os problemas sejam superados, o que nem sempre ocorre de forma tranquila porque as diferenças de contexto podem retrair o sujeito. Dependendo da trajetória do acadêmico, ele precisa ser amparado nesse movimento para que não abandone o curso escolhido e veja frustrado o projeto de cursar a Educação Superior.

O nível de autonomia do estudante, por exemplo, interferirá na aceitação de novos hábitos e atitudes, assim como seu modo de perceber a vida e seu entorno interferirão no percurso. A passagem do Ensino Médio para a Universidade dá-se, portanto, por diferentes vias, dependendo da história de vida dos sujeitos, assim como dos mediadores que se encontram nessas vias. Nelas se entrelaçam corpo docente, coordenação de curso, colegas, o suporte oferecido pela instituição, os serviços prestados pelas gerências, e, também, a própria infraestrutura física da universidade, entre outros elementos e mediadores que interferirão nessa trajetória.

Essa transição é dependente, portanto, não apenas da formação dos ingressantes, mas também da estrutura que os acolhe. Evidentemente que ela ocorre de forma mais equilibrada quando o acadêmico apresenta um perfil mais próximo do esperado pela universidade, como é o caso do conhecimento em língua estrangeira. Ao analisarmos os dados coletados na pesquisa em foco, observamos que o maior índice de conhecimento em língua estrangeira diz respeito à língua inglesa, seguida da língua espanhola. Na terceira posição, aparece a opção "Não possuo" [conhecimento em língua estrangeira], como podemos observar no gráfico a seguir.

Gráfico 9: Conhecimento em língua estrangeira

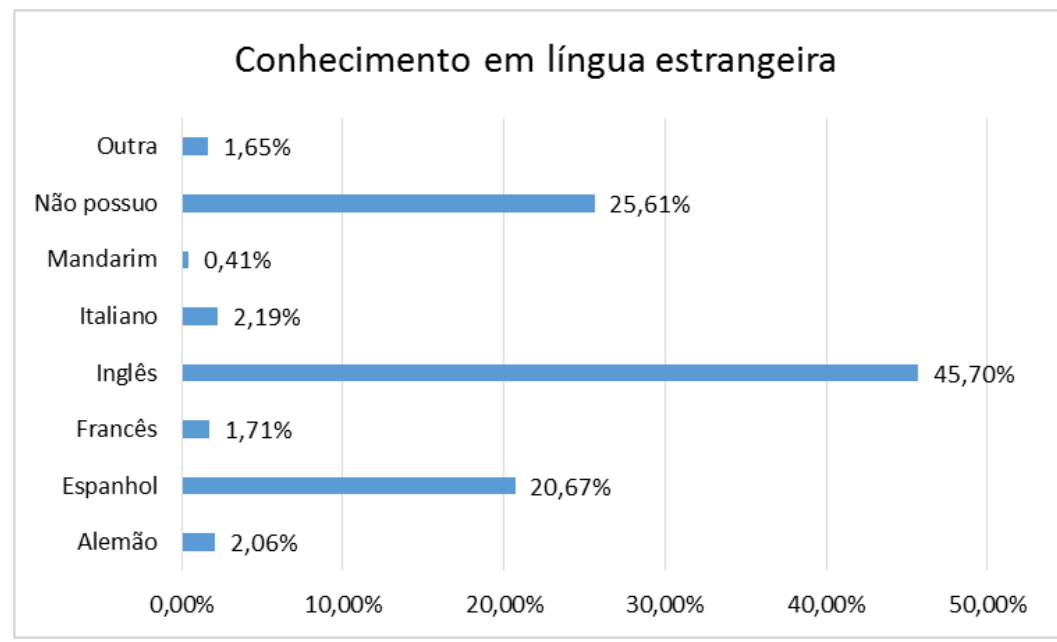

Fonte: Vice-Reitoria de Graduação e Gerência de Ensino e Avaliação da universidade investigada/2016.

Identificamos que $66,70 \%$ dos ingressantes possuem conhecimento em língua estrangeira. Esse perfil dos acadêmicos é influenciado, entre outros fatores, pelo advento da
(C) ETD-Educação Temática Digital
Campinas, SP
v. 20
n.3
p. $781--804$
jul./set. 2018 
internet, pois $77,03 \%$ dos pesquisados têm acesso a essa rede em casa, 39,02\% possuem smartphone e $33,68 \%$, notebook. Além disso, 31,58\% sinalizaram que utilizam a internet de 3 a 5 horas por dia; 26,19\%, de 6 a 9 horas e 16,03\%, acima de 12 horas.

A popularização das tecnologias de comunicação e a variedade de ferramentas comunicativas disponíveis, em especial os dispositivos móveis como o smartphone e o notebook, marcam um avanço na comunicação. Aderaldo e Raposo (2016, p. 282) apontam como o acesso aos meios digitais promoveu a expansão da circulação de símbolos, aumentando as trocas simbólicas entre as pessoas jovens e "[...] habitantes de áreas socialmente marcadas por processos de precarização". Para os autores, a internet permitiu que os jovens expandissem seus circuitos de sociabilidade e estimulou "[...] verdadeiros câmbios de conhecimento sobre o espaço urbano e os modos de administração política de suas fronteiras" (ADERALDO; RAPOSO, 2016, p. 282). Essa mudança de comportamento, tendo em vista a habilidade do jovem no uso das tecnologias, estende seus reflexos aos hábitos relacionados ao uso de recursos para estudar.

Em nossa pesquisa, $37,90 \%$ sinalizam que fazem uso dos aplicativos didáticos computacionais; $26,72 \%$, de anotações pessoais; $21,16 \%$, de livros; $9,85 \%$, de apostilas; e $4,37 \%$, de artigos e revistas.

Gráfico 10: Recursos empregados para estudo

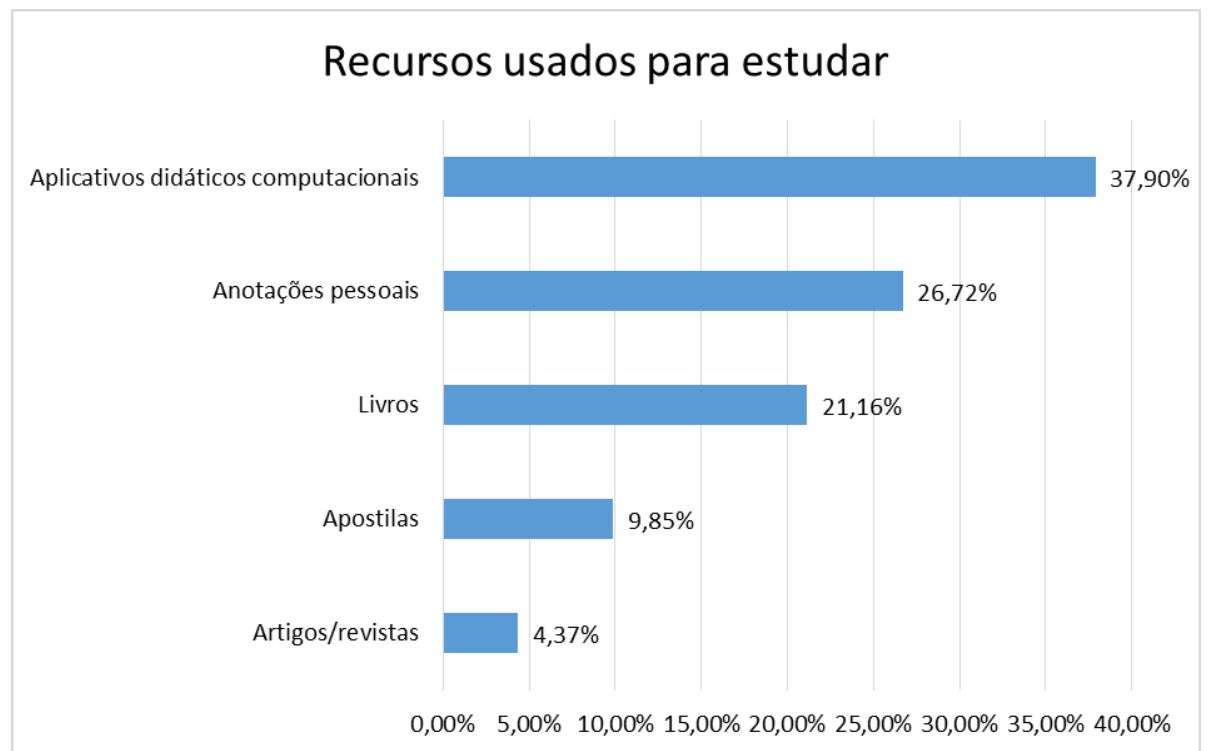

Fonte: Vice-Reitoria de Graduação e Gerência de Ensino e Avaliação da universidade investigada/2016.

Constatamos, assim, que os recursos didáticos mais usados são os tecnológicos, seguidos de anotações próprias (muitas vezes feitas no próprio aplicativo do celular e do notebook) e de livros. Isso se justifica, uma vez que: “O mundo virtual desencadeou uma série de modificações no cotidiano do jovem, no que tange a suas relações, no contato com

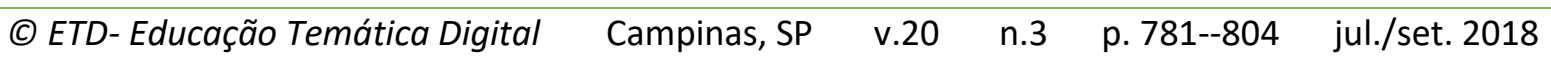


as informações, na forma de aprender, de produzir significados e conhecimentos" (ZLUHAN; VANZUITA; RAITZ, 2017, p. 209). Se esse resultado aponta para o desafio que a universidade enfrenta, de expandir entre os professores o uso de aplicativos didáticos computacionais como ferramenta para atividades auxiliares no processo de ensino e aprendizagem, também sinaliza a necessidade de inserir os jovens na cultura impressa, pois esta faz parte da rede de relações tecida pela universidade. Ainda no que diz respeito aos recursos empregados para estudo, identificamos que a opção "Artigos/revistas" é a menos sinalizada pelos estudantes. Esse dado indica que a universidade necessita empreender ações para mobilizar os docentes a utilizarem esses recursos em sala de aula, pois, em uma era altamente tecnológica, em que há diversas revistas on-line, sem custos, assim como repositórios em bibliotecas, não se justifica o baixo índice na utilização desse tipo de material.

Para que essa rede seja ampliada e para que esses câmbios de conhecimento sejam efetivados, além da posse de dispositivos tecnológicos e digitais, é relevante o domínio de uma língua estrangeira. Assim, a tecnologia contribui para que as fronteiras sejam diminuídas e os jovens tenham a necessidade de aprender um outro idioma. Cumpre lembrar que políticas públicas motivaram muitos estudantes do Ensino Médio e do Ensino Superior a aprender uma língua estrangeira. Archanjo (2016) discute sobre a mobilidade acadêmica como instrumento de desenvolvimento e produção do conhecimento técnico, científico e de inovação no Brasil por meio de dois programas públicos de fomento à internacionalização: "Ciência sem Fronteiras" e "Idiomas sem Fronteiras".

Para o pesquisador, na atualidade, as línguas "[...] adquirem valores de mercado, para além de seu valor como um bem cultural" (ARCHANJO, 2016, p. 517). Aprender uma língua estrangeira significa ampliar a possibilidade de compreensão do mundo e, por isso, amplia o poder do falante. "Tais sentidos estão muito mais facilmente encharcados pela ideologia das forças do mercado globalizado para o qual a língua é também poder" (ARCHANJO, 2016, p. 519). Como resultado dos programas públicos de fomento à internacionalização, houve um movimento no país de oferecimento de estudos em línguas estrangeiras, em especial a língua inglesa, mobilizando, assim, os estudantes para o desafio de ampliar seu poder por meio do domínio de uma língua. Trata-se, portanto, de uma política linguística que é viabilizada por meio de uma política pública de mobilidade acadêmica, a qual interfere na forma como os acadêmicos interagem com seus pares, alterando suas relações pessoais e profissionais, assim como a forma como recebem e processam informações, críticas, sugestões, orientações.

A seguir, apresentaremos as interferências às quais o potencial acadêmico se expõe ao fazer suas escolhas, como ele é informado sobre a universidade e os cursos de graduação

$\begin{array}{llllll}\text { (C) ETD-Educação Temática Digital } & \text { Campinas, SP } & \text { v.20 } & \text { n.3 } & \text { p. 781--804 } & \text { jul./set. } 2018\end{array}$


disponíveis, os motivos que influenciam sua tomada de decisão, as expectativas dele com relação ao curso, assim como a região geográfica de procedência do estudante.

\subsection{Escolhas e expectativas do universitário ingressante}

O processo de escolha profissional não é uma tarefa fácil, principalmente se a escolha tiver que ser feita antes dos 20 anos de idade, quando o sujeito passa por vários conflitos emocionais, mudanças físicas, dúvidas e paradoxos, "[...] multiplicidades e pluralidades que integram o mosaico juvenil" (ZLUHAN; VANZUITA; RAITZ, 2017, p. 214).

Paralelamente à decisão pela profissão, é necessário optar por uma instituição de ensino. Como a pessoa jovem escolhe sua profissão e a universidade? Como obtém informações detalhadas sobre o mundo profissional em que pretende ingressar? Quais suas expectativas? Para Gatti (2000, p. 107), a questão da qualidade real (que nem sempre faz parte das propagandas dos cursos) é um dos critérios que precisa acompanhar os jovens para que o diploma não seja o mais visado nesse percurso acadêmico, mas, sim, as "possibilidades de aprendizagem diferencial."

Ao questionarmos os ingressantes quanto aos meios que lhes permitiram ter acesso a informações sobre a universidade escolhida, identificamos que, para $46,47 \%$ dos respondentes - apesar de estarem constantemente conectados aos meios digitais, às redes sociais - a informação mais ouvida sobre a universidade ainda vem do tradicional "boca-aboca", colhido no ambiente familiar e escolar. Observamos que os meios com menos impacto sobre o público-alvo da pesquisa são rádio, jornal e TV.

Gráfico 11 - Principais canais de informação sobre a IES

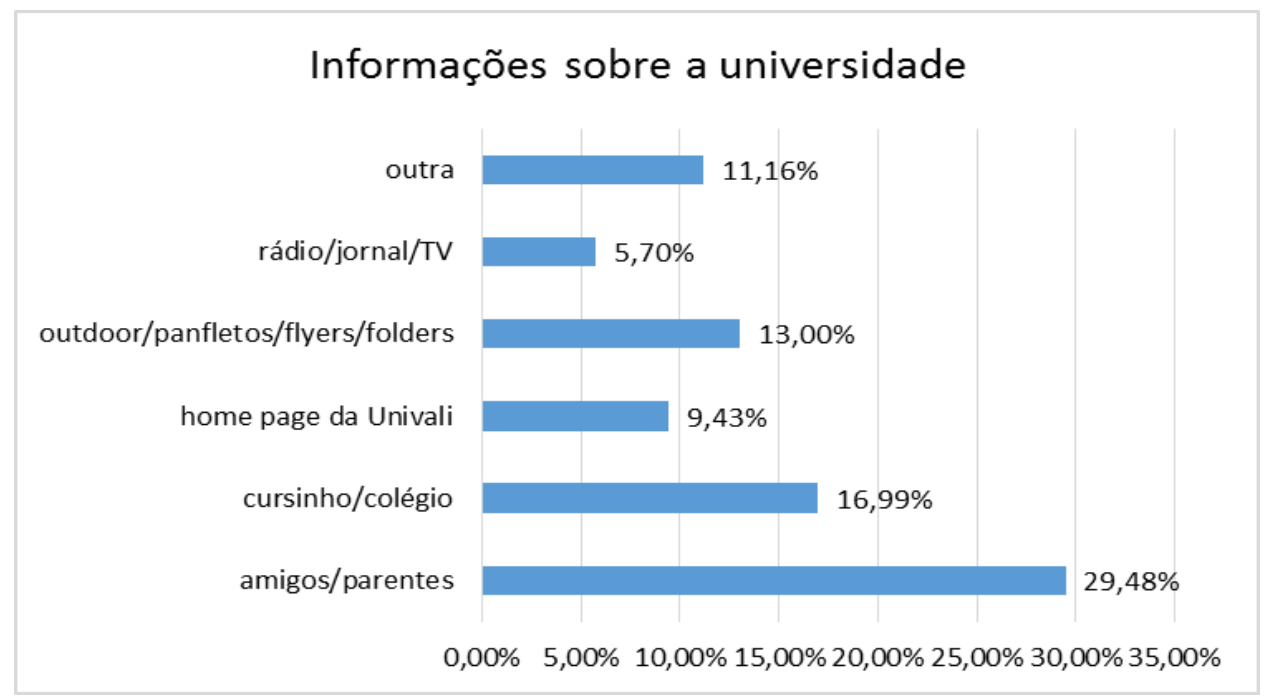

Fonte: Vice-Reitoria de Graduação e Gerência de Ensino e Avaliação da universidade investigada/2016.

(C) ETD- Educação Temática Digital Campinas, SP $\quad$ v.20 $\quad$ n.3 $\quad$ p. $781--804 \quad$ jul./set. 2018


Quando interrogados sobre o motivo da opção pela universidade em que ingressaram, 54,64\% remetem à qualidade institucional ("Universidade que oferece o melhor curso"); $31,45 \%$ indicam que a escolha se deu pela proximidade do local onde moram; $11,26 \%$, por ser o único curso oferecido na região; e 2,65\%, pelo valor da mensalidade compatível com o orçamento.

Gráfico 12 - Razões apontadas pelos ingressantes para escolher a IES

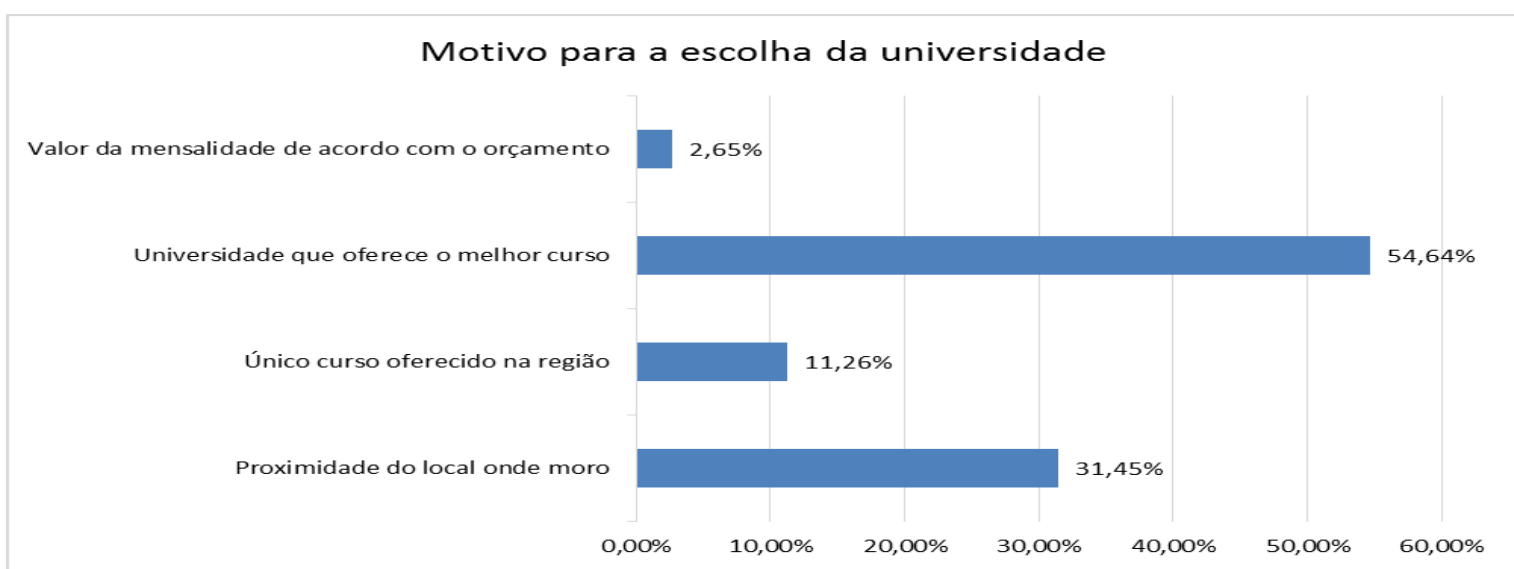

Fonte: Vice-Reitoria de Graduação e Gerência de Ensino e Avaliação da universidade investigada/2016.

Esse resultado aponta que a escolha da instituição não se dá, na maioria dos casos, pelo valor da mensalidade, mas pelas oportunidades que a instituição pode oferecer. São decisivas para essa escolha: oportunidades de estágio, extensão, pesquisa, assim como a qualificação dos docentes, que implica também o direcionamento da carreira do acadêmico.

A indicação de que a escolha da universidade é motivada também pela proximidade geográfica entre a residência do ingressante e a instituição de ensino revela uma característica da geração atual, que é o desejo de continuar morando com a família. Se, por um lado, os não deslocamentos de moradia evitam alterações em padrões e estilos de vida para os acadêmicos e uma economia para a família; por outro, sinalizam uma dependência dos jovens, que retardam sua saída de casa. Se, no passado, "[c]hegar à fase adulta era um grande sonho, pois os jovens poderiam finalmente agir com autorregulação", como apontam Zluhan, Vanzuita e Raitz (2017, p. 208), hoje eles já não aderem a comportamentos e ideias opostas às gerações anteriores. A permanência na família pode ser uma das causas, segundo os pesquisadores, da falta de autonomia dos jovens, porque eles deixam de aprender a resolver os conflitos que envolvem essa fase, tais como a frustração, a raiva, a revolta. Estes são "[...] sentimentos que precisam ser vividos e por isso, [no passado], os pais não buscavam estratégias para poupar os filhos dessas emoções" (ZLUHAN; VANZUITA; RAITZ, 2017, p. 206-207), o que não acontece na atualidade.
(C) ETD-Educação Temática Digital
Campinas, SP
v. 20
n.3
p. $781--804$
jul./set. 2018 
A permanência na família, portanto, passou a fazer parte da cultura da juventude no século XXI, e a escolha da universidade também se dá pela situação geográfica da instituição. Observamos que apenas 3,98\% dos ingressantes vêm da Região Sudeste e menos de $4 \%$ de outras regiões. A grande maioria dos ingressantes, 92,54\%, procedem da Região Sul: 82,99\%, de Santa Catarina; 5,79\%, do Rio Grande do Sul; e 3,75\%, do Paraná. Identificamos, ainda, que, da grande maioria que é proveniente do estado de Santa Catarina, 61,67\% residem na mesorregião do litoral norte do Vale do Itajaí; 19,70\%, na Grande Florianópolis; 9,42\%, no Baixo Vale do Itajaí; 3,21\%, no norte do estado; $2,30 \%$, no oeste catarinense; e $1,55 \%$, na região serrana de Santa Catarina.

Ao serem questionados sobre como foram informados sobre o curso, os ingressantes apontam a internet como o meio de informação mais consultado, ultrapassando inclusive a influência da família e do colégio/cursinho. Ainda, constatamos que as atividades desenvolvidas na universidade, em especial o Programa de Orientação Profissional por Área (OPA), exercem grande influência na escolha, pois mais de um quarto dos ingressantes colheram nesses espaços informações sobre o curso.

Gráfico 13 - Principais canais de informação sobre o curso

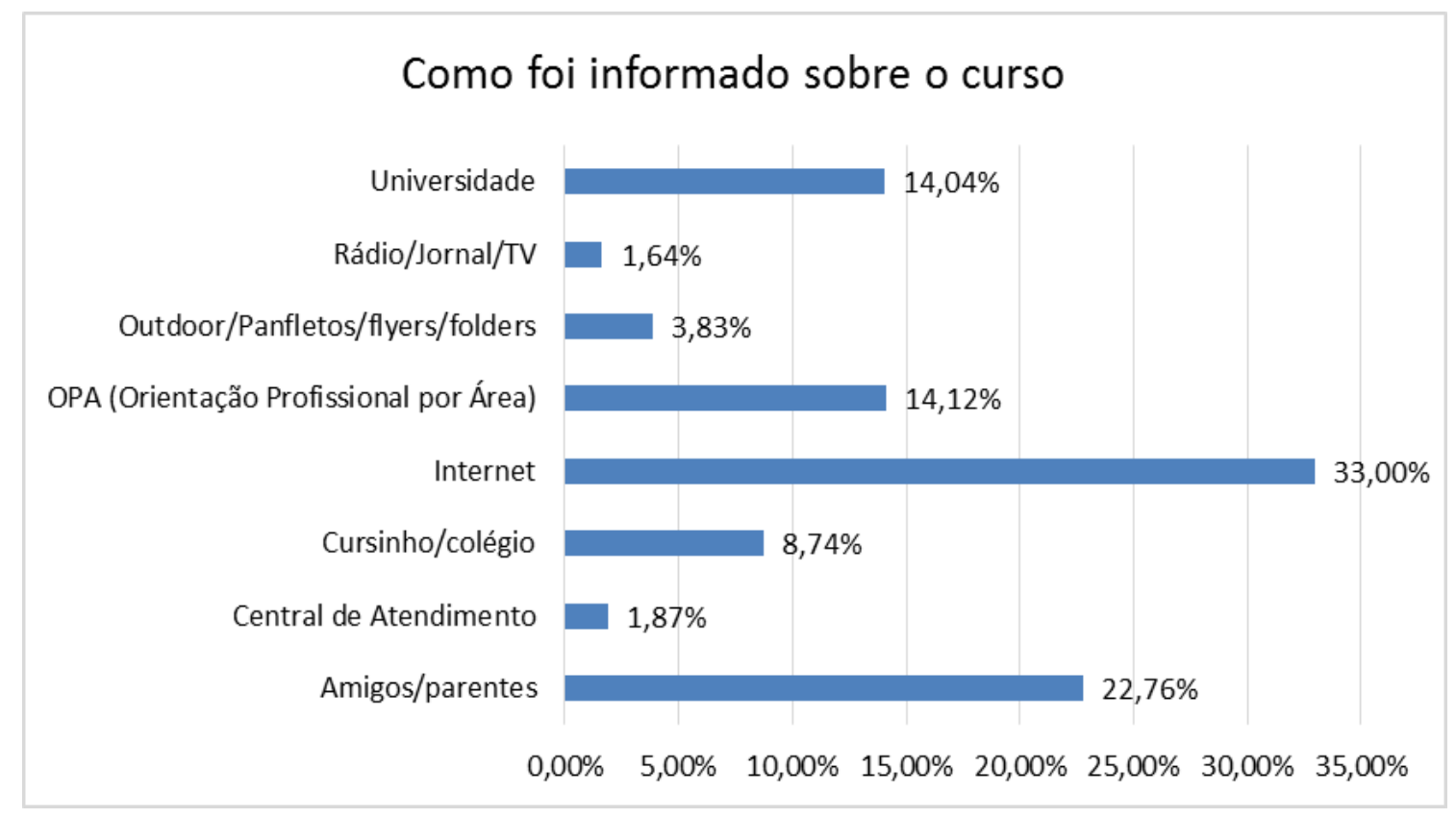

Fonte: Vice-Reitoria de Graduação e Gerência de Ensino e Avaliação da universidade investigada/2016.

Ao analisarmos o Gráfico 14, a seguir, sobre a principal motivação para a escolha do curso, constatamos que a resposta "Identificação profissional com a área ou profissão" vem em primeiro lugar entre as opções, com 65,50\%, seguida do indicador "Família", com $10,07 \%$.
(C) ETD-Educação Temática Digital
Campinas, SP
v. 20
n.3
p. $781--804$
jul./set. 2018 


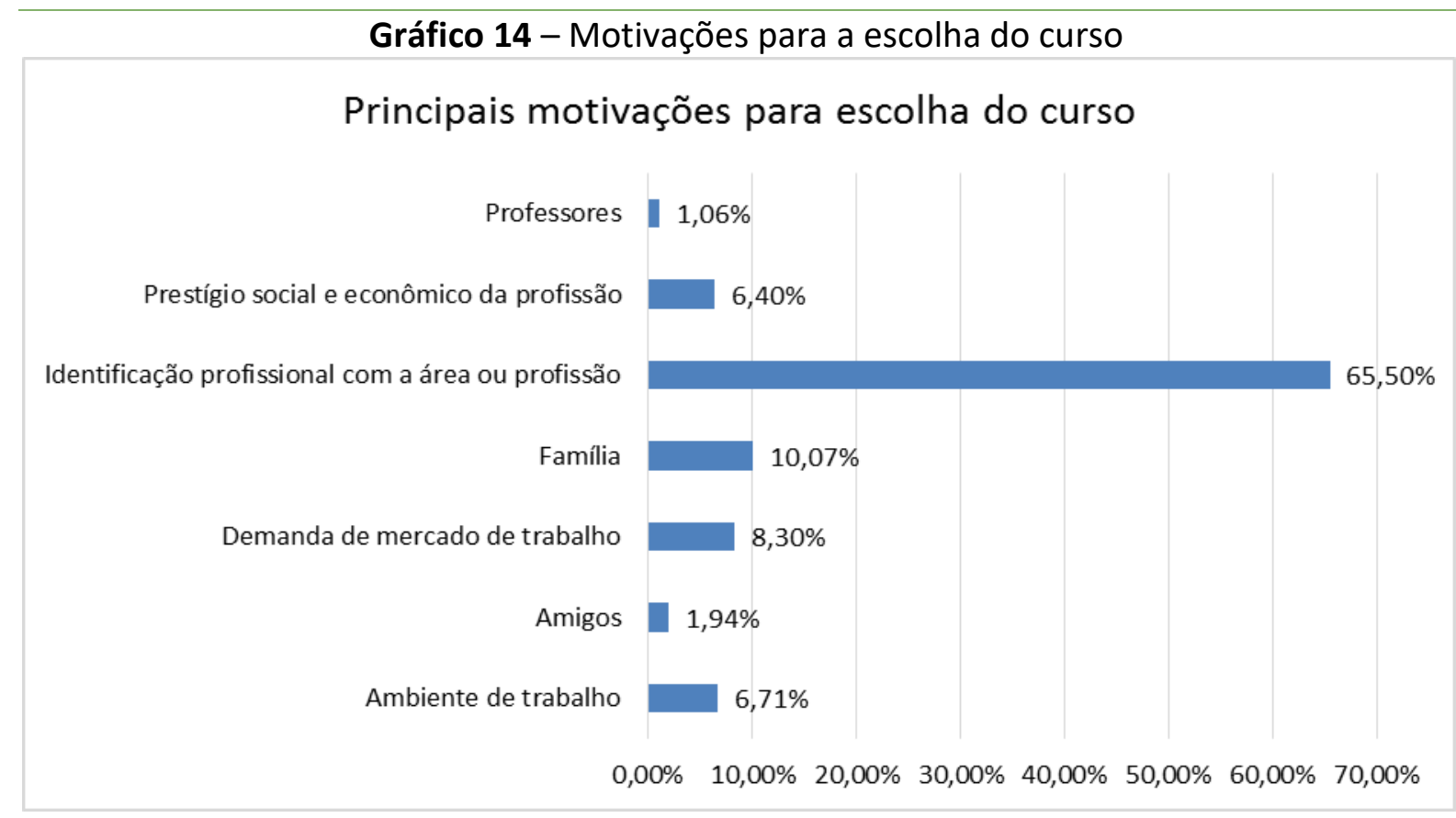

Fonte: Vice-Reitoria de Graduação e Gerência de Ensino e Avaliação da universidade investigada/2016.

Ao cruzarmos os dados sobre a motivação para a escolha da universidade com os resultados obtidos quanto à escolha do curso, podemos inferir que a opção pela universidade é determinante, ou seja, o jovem pode se decidir, em primeiro lugar, pela universidade e, posteriormente, buscar no rol de cursos da instituição aquele com que mais se identifica. Esse dado revela que o jovem se preocupa não apenas em obter uma certificação adequada ao seu desejo profissional, mas em conquistar uma formação sólida em uma instituição qualificada, pois suas escolhas são influenciadas pelas informações sobre a instituição e sobre o curso que deseja frequentar, aliadas ao propósito de permanecer morando com a família.

Percebemos, assim, que o acesso à informação auxilia o ingressante a ter autonomia, tornando menos decisiva a influência dos parentes e amigos na escolha do curso, mas estes ainda exercem grande influência na opção pela universidade. Se somarmos o percentual que declarou ter conhecido o curso por meio do OPA e da universidade, podemos observar que $28,16 \%$ decidiram-se pelo curso após conhecerem com mais propriedade as condições da instituição, o que possibilita uma transição do Ensino Médio para o Superior com mais motivação e segurança.

Se, no passado, a universidade era percebida como local, por excelência, do saber científico, onde cada ciência tinha seu lugar muito demarcado, hoje surgiram "[...] novos campos de conhecimento e estes são diretamente transversalizados com a evolução tecnológica" (ZLUHAN; VANZUITA; RAITZ, 2017, p. 208). Deparamo-nos com a necessidade

(C) ETD-Educação Temática Digital $\quad$ Campinas, SP $\quad$ v.20 $\quad$ n.3 $\quad$ p. 781--804 jul./set. 2018


de uma universidade que proponha uma formação não só voltada para a especialidade escolhida, mas multidisciplinar, que prepare o jovem para adaptar-se às diversas situações. Essa visão encontra respaldo nas respostas dos pesquisados que, ao serem questionados sobre a principal expectativa em relação ao curso, concentraram as respostas em dois indicadores: "Conhecimento específico da área e cultura geral", e "Habilitação para diferentes possibilidades profissionais".

Gráfico 15: Expectativas em relação ao curso

\section{Principais expectativas com relação ao curso}

Conhecimento específico da área e cultura gera

Hab. p/ diferentes possibilidades profissionais

Melhoria na situação profissiona

Outras

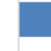

$0,00 \%$
$9,54 \%$

$12,63 \%$

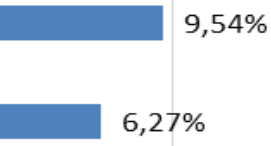

$10,00 \% \quad 20,00 \%$
$36,79 \%$

$34,76 \%$

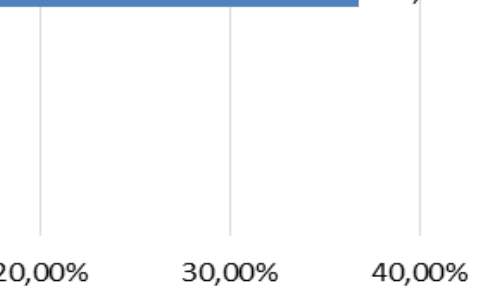

Fonte: Vice-Reitoria de Graduação e Gerência de Ensino e Avaliação da universidade investigada/2016.

O Gráfico 15 convida-nos a refletir sobre o que o curso ensina e como ensina, buscando ênfases curriculares mais adequadas para a formação do estudante universitário. Além de conhecimentos específicos da área de atuação, esse jovem anseia por uma formação geral, com conhecimentos amplos que o preparem para ser um cidadão do mundo, com porosidade profissional, uma visão ampliada da área que escolheu e que the permita adentrar em diversos setores da área escolhida. Nesse sentido, a participação em pesquisas e projetos culturais e de extensão universitária assim como a oferta de disciplinas de formação geral poderão ser percebidas como oportunidades educacionais que ampliam os hábitos culturais, a formação e as possibilidades de atuação profissional do estudante.

Ao compreendermos como o jovem faz suas escolhas, quais recursos ele utiliza para estudar, conheceremos suas necessidades e poderemos mais facilmente auxiliá-lo a se apropriar da cultura universitária e dela fazer parte ativamente, o que nos permite afirmar que: "A perspectiva desse processo avaliativo é essencialmente pedagógica, não numa perspectiva punitiva, mas, sim, orientadora" (GATTI, 2000, p. 106). A pesquisa de Mendes e Costa (2015) sinaliza como os hábitos culturais dos jovens os influenciam em seu acesso ao Ensino Superior, situando o papel da educação como fator de estratificação social. Para os
(C) ETD-Educação Temática Digital
Campinas, SP
v. 20
n. 3
p. $781--804$
jul./set. 2018 
pesquisadores, "[...] as condições escolares e os fatores como competência e esforço individual não são os únicos - ou os principais - determinantes das realizações educacionais" (MENDES; COSTA, 2015, p. 73). Entre os elementos determinantes, encontra-se o capital cultural, sinalizado pelos autores como um fator que não recebe "[...] a mesma atenção que os fatores econômicos e geralmente é medido nas pesquisas pela indicação da escolaridade dos pais e nada mais" (MENDES; COSTA, 2015, p. 73). Dessa forma, assinalamos que o acolhimento aos ingressantes na universidade implica não somente políticas afirmativas, mas também ações de nivelamento sobre determinados conteúdos básicos e ações que impactem o capital cultural dos estudantes.

Como limitações a esta pesquisa, citamos a questão 17 do questionário on-line aplicado junto aos ingressantes. Essa questão perguntava o tempo que o acadêmico dedicava ao estudo e à leitura extra-aula, sem mencionar a que tipo de leitura se referia, funcional ou literária, nem ao suporte, impresso ou digital, dificultando a interpretação.

Em síntese, como resultados, sinalizamos: a) o perfil dos ingressantes revela, entre outros dados, que a maioria é do sexo feminino, economicamente dependente da família e oriunda de escolas públicas; b) a participação dos ingressantes pesquisados em atividades culturais, como teatro, cinema, shows e em atividades de lazer como a prática de esportes, dança e academia, é moderada; c) ações de acolhimento e atendimento ao discente na instituição e no curso são fundamentais para que a transição do Ensino Médio para o Ensino Superior seja vivida de forma mais tranquila pelo acadêmico e também para a permanência dele na universidade; d) a maioria deseja desenvolver habilidades para diferentes possibilidades profissionais e adquirir conhecimentos da área de cultura geral.

Observamos que o processo de transição de uma etapa escolar para a outra é dependente não apenas da formação dos ingressantes, mas também da estrutura que os acolhe. Uma avaliação dessa natureza amplia as possibilidades dos estudantes porque ela auxilia no "[...] processo de ampliação das possibilidades humanas, com qualidade crescente" (GATTI, 2000, p. 96) e não limita as potencialidades dos envolvidos. A universidade precisa atuar como um campo de formação específica e, também, oferecer oportunidades de ampliar o capital cultural dos estudantes.

\section{CONSIDERAÇÕES FINAIS}

Ao longo desta análise, destacamos elementos que caracterizam o perfil do discente ingressante em uma universidade comunitária no estado de Santa Catarina, na Região Sul do Brasil, com o intuito de pontuar as pluralidades que compõem o mosaico juvenil e envolvem a transição do Ensino Médio para o Superior. O reconhecimento desses elementos permite-

(C) ETD-Educação Temática Digital Campinas, SP $\quad$ v.20 $\quad$ n.3 $\quad$ p. 781--804 jul./set. 2018


nos refletir sobre os paradoxos envolvidos nessa transição e ousar ações de equilíbrio, como sugerem Zluhan, Vanzuita e Raitz (2017), que auxiliem na redução dos índices de abandono e evasão nos primeiros anos dos cursos superiores. Por essas razões, os achados deste estudo podem contribuir para as demais instituições de Ensino Superior e para a pesquisa na área.

Para discutir sobre o período de transição vivido pelo acadêmico ingressante e sobre as complexidades que envolvem a permanência dele na universidade, buscamos entender elementos da cultura juvenil do ponto de vista histórico, econômico, cultural e social. Compreender essa transição é fundamental porque "[...] as transições tratam de orientar e formar as pessoas para que adquiram a capacidade de abordar e viver novos desafios, valorizando suas potencialidades" (RAITZ, 2012, p. 28). Do ponto de vista da gestão institucional, as informações sobre hábitos e situação econômica, social e cultural dos ingressantes são instrumentos que possibilitarão criar estratégias, tanto para que as oportunidades de acesso sejam reais oportunidades de realização dos projetos pessoais desse público, como para diminuir os índices de reprovação, de desistência e/ou evasão nos primeiros períodos dos cursos de graduação.

Aumentar o número de matriculados na Educação Superior é uma das metas do Plano Nacional da Educação (PNE); elevar o grau de satisfação dos acadêmicos com as instituições de ensino é uma das possibilidades de alcançar-se essa meta. Esses jovens estão em movimento, e a participação deles na comunidade universitária não é mais impulsionada apenas pelo objetivo de sucesso profissional, mas por identificação profissional. São jovens que pesquisam sobre o curso pelo qual optaram e almejam ser felizes. Por isso, a universidade é um espaço que não pode se limitar à reprodução de informações ou de conhecimentos. Deve, sim, incentivar a convivência, a produção, a troca, o diálogo, a articulação de saberes, o que exige uma constante reinvenção do ato de educar.

Todas essas constatações, ao serem difundidas, podem provocar um movimento que permitirá aos gestores e aos professores projetar ações que agreguem oportunidades para o acadêmico expandir sua permanência e integração na Educação Superior, as quais passam por metas articuladas que levem à qualidade do processo de ensino e aprendizagem, ao atendimento ao discente, ao acesso a serviços e a bens culturais.

\section{REFERÊNCIAS}

ADERALDO, Guilhermo; RAPOSO, Otávio. Deslocando fronteiras: notas sobre intervenções estéticas, economia cultural e mobilidade juvenil em áreas periféricas de São Paulo e Lisboa. Horizontes Antropológicos, Porto Alegre, v. 22, n. 45, p. 279-305, jan./jun. 2016. DOI: http://dx.doi.org/10.1590/S0104-7183201600010001
(C) ETD-Educação Temática Digital
Campinas, SP
v. 20
n. 3
p. $781--804$
jul./set. 2018 
ARCHANJO, Renata. Saberes sem Fronteiras: Políticas para as migrações Pós-modernas. DELTA: Documentação de Estudos em Linguística Teórica e Aplicada, São Paulo, v. 32, n. 2, p. 515-541, maio/ago. 2016. DOI: http://dx.doi.org/10.1590/0102-4450790718885409696

BRASIL. Constituição (1988). Constituição da República Federativa do Brasil. Brasília, DF: Senado Federal: Centro Gráfico, 1988. 292 p.

Lei № 12.852, de 5 de agosto de 2013. Institui o Estatuto da Juventude e dispõe sobre os direitos dos jovens, os princípios e diretrizes das políticas públicas de juventude e o Sistema Nacional de Juventude - SINAJUVE. Diário Oficial [da] República Federativa do Brasil, Poder Legislativo, Brasília, DF, 6 ago. 2013. Seção 1, n. 150, p. 1-4.

BRASIL. Lei № 13.005, de 25 de junho de 2014. Aprova o Plano Nacional de Educação - PNE e dá outras providências. Diário Oficial [da] República Federativa do Brasil, Poder Legislativo, Brasília, DF, 26 jun. 2014. Seção 1, n. 120-A, edição extra, p. 1-7.

BRIDON, Janete; NEITZEL, Adair de Aguiar. Competências leitoras no Saeb: qualidade da leitura na educação básica. Educação \& Realidade, Porto Alegre, v. 39, n. 2, p. 437-462, abr./jun. 2014. DOI: http://dx.doi.org/10.1590/S2175-62362014000200006

BRUSCHINI, Maria Cristina Aranha. Trabalho e gênero no Brasil nos últimos dez anos. Cadernos de Pesquisa, São Paulo, v. 37, n. 132, p. 537-572, set./dez. 2007.

GATTI, Bernadete A. Avaliação institucional e acompanhamento de instituições de educação superior: estudos em avaliação educacional. Revista em Avaliação Educacional, São Paulo, n. 21, p. 93-107, 2000. DOI: http://dx.doi.org/10.18222/eae02120002227

GAGNÉ, Ellen D.; YEKOVICH, Carol Walker; YEKOVICH, Frank R. The cognitive psychology of school learning. 2. ed. New York, USA: Harper Collins, 1993.

INEP. Instituto Nacional de Estudos e Pesquisas Educacionais Anísio Teixeira. Sinopse Estatística da Educação Superior 2015 [on-line]. Brasília: Inep, 2016. Disponível em: http://portal.inep.gov.br/basica-censo-escolar-sinopse-sinopse. Acesso em: 13 abr. 2017.

IBGE. Pesquisa nacional por amostra de domicílios 2015/PNAD. Disponível em: http://www.ibge.gov.br/home/estatistica/populacao/trabalhoerendimento/pnad2015/brasil defaultxls.shtm. Acesso em: 21 fev. 2017.

LUCENA, Simone. Culturas digitais e tecnologias móveis na educação. Educar em Revista, Curitiba, n. 59, p. 277-290, jan./mar. 2016. DOI: 10.1590/0104-4060.43689

MENDES, Igor A. Assaf; COSTA, Bruno Lazzarotti D. Considerações sobre o papel do capital cultural e acesso ao Ensino Superior: uma investigação com dados de Minas Gerais.

Educação em Revista, Belo Horizonte, v. 31, n. 3, p. 71-95, jul./set. 2015. DOI: http://dx.doi.org/10.1590/0102-4698135457
(C) ETD- Educação Temática Digital
Campinas, SP
V. 20
n.3
p. 781--804
jul./set. 2018 
NEITZEL, Adair de Aguiar; CARVALHO, Carla; BRIDON, Janete. (Orgs.). Cultura, escola e educação criadora: formação estética e saberes sensíveis. Itajaí: UNIVALI; Joinville: UNIVILLE, 2015.

POULAIN, Martine. Entretien. In: BESSARD-BANQUY, Olivier. Les mutations de la lecture. Bordeaux: Presses Univ. de Bordeaux, 2012. p. 69-83.

RAITZ, Tânia Regina. Entre o hoje e o amanhã: estudo sobre os fatores e os novos rumos da transição universitária ao mundo do trabalho. 2012. 106 f. Relatório Pós-doutoral. (Pósdoutorado em Educação) - TRALS - Transiciones Acadèmicas e Laborales, Barcelona, 2012.

RAITZ, Tânia Regina; FIGUERA-GAZO, Maria Pilar. Transições dos estudantes: reflexões ibero-americanas. Curitiba: CRV, 2015.

SILVA FILHO, Luís Abel da; QUEIROZ, Silvana Nunes de; CLEMENTINO, Maria do Livramento Miranda. Mercado de trabalho nas regiões metropolitanas brasileiras. Mercator, Fortaleza, v. 15, n. 2, p. 37-54, jun. 2016. DOI: 10.4215/RM2016.1502. 0003

TRALS. Grup de Recerca sobre Transicions Acadèmiques i Laborals. El rendiment acadèmic i la trajectória acadèmica en els dos primers anys de la universidad. Barcelona: Universitat de Barcelona, 2002.

URIARTE, Mônica; NEITZEL, Adair de Aguiar; CARVALHO, Carla. Mediação cultural: função de mestre explicador ou ação de mestre emancipador? In: NEITZEL, Adair de Aguiar;

CARVALHO, Carla. (Orgs.). Mediação cultural, formação de leitores e educação estética. Curitiba: CRV, 2016. p. 37-53.

VANZUITA, Alexandre et al. Uma discussão sobre trajetórias escolares na atualidade: do Ensino Médio ao Ensino Superior. Revista Espacios [online], v. 37, n. 33, 2016. Disponível em: http://www.revistaespacios.com/a16v37n33/16373301.html . Acesso em: 20 maio 2017.

ZLUHAN, Mara Regina; RAITZ, Tânia Regina. Um estudo com jovens: transição do Ensino Médio ao Ensino Superior. In: ANPED SUL, 10., 2014, Florianópolis. Anais eletrônicos... Florianópolis: Associação Catarinense de Medicina, 2014. Disponível em: http://xanpedsul.faed.udesc.br/arq pdf/325-0.pdf. Acesso em: 21 fev. 2017.

ZLUHAN, Mara Regina; VANZUITA, Alexandre; RAITZ, Tânia Regina. Da modernidade à pósmodernidade: experiências e significados juvenis. Revista Reflexão e Ação, Santa Cruz do Sul, v. 25, n. 1, p. 198-217, jan. /abr. 2017. DOI: http://dx.doi.org/10.17058/rea.v25i1.7436

'Revisão gramatical do texto sob a responsabilidade de: Janete Bridon - Graduada em Letras Português e Letras Inglês. Mestre em Educação. E-mail: www.deolhonotexto.com.br ; deolhonotexto@gmail.com

\footnotetext{
ii Esta pesquisa contou com a participação dos pesquisadores Maria Elisabeth P. Kraemer e Nilmar de Souza para tabulação dos dados.
}

(C) ETD-Educação Temática Digital $\quad$ Campinas, SP $\quad$ v.20 $\quad$ n.3 $\quad$ p. 781--804 jul./set. 2018 